\title{
Justicia de Género: autonomía feminista frente a la violencia machista e institucional
}

\author{
Por Milena Úngaro
}

\section{Introducción}

Como hemos escuchado incansablemente durante nuestros años de formación académico-jurídica, el acceso a la justicia constituye un derecho humano fundamental cuyo arraigo se encuentra consagrado en nuestra Constitución Nacional y en los Tratados Internacionales de idéntica jerarquía introducidos por la reforma de 1994, según el artículo 75 inciso 22 del mismo texto legal ${ }^{1}$.

Las incidencias sociales y culturales históricas, sin embargo, han generado distancias abismales entre el ser y el deber ser, provocando la sistemática vulneración de derechos de los sectores menos favorecidos. Al respecto, uno de los conglomerados sociales que mayor afectación ha padecido es el de las mujeres.

Sería inocente pensar que el problema de la discriminación sexual o de género se limita a cuestionar la ineficiente aplicación del derecho a la igualdad o el acceso a los tribunales de justicia. Para lograr comprender este fenómeno se requiere de un estudio histórico, profundo y exhaustivo de los patrones culturales que han ido transformando la realidad social, hasta situarnos en el mundo tal cual hoy lo conocemos.

Para comprender acabadamente la problemática sobre el defectuoso acceso a la justicia sufrido por las mujeres, el tema puede ser abordado desde una perspectiva feminista, tomando en cuenta la manifiesta brecha social existente en razón del género ${ }^{2}$. Por otra parte, es menester destacar que el análisis del tema debe circunscribirse en el contexto latinoamericano, como resultado de las características propias que reviste la problemática en este lado del continente.

Constituyen patrones discriminatorios todos aquellos que establecen que ciertas actividades, comportamientos o valores, son "típicamente femeninos", o cuando se

1 Respecto a la violencia vinculada con cuestiones de género, la problemática se encuentra especialmente receptada en la Convención Interamericana para prevenir, sancionar y erradicar la violencia contra la mujer, conocida como "Convención Belém Do Para". En el orden nacional, rige la Ley 26.485.

2 Este término debe entenderse considerando la disputa de poder propia de las estructuras culturales y no como una pretendida polaridad biológica. Una de las primeras autoras en desarrollar este concepto fue Ann Oakey en su obra Sex, Gender and Society (1972). Su incorporación al lenguaje jurídico se produjo a mediados de la década de 1990, al introducirse respuestas legales a la problemática sobre violencia hacia las mujeres. 
asignan roles o funciones subordinadas y estereotipadas a las mujeres, y cuando dicha asignación es naturalizada sin cuestionamiento alguno.

En general, estas desigualdades se materializan como obstáculos o dificultades que las mujeres afrontamos para acceder a determinadas áreas, actividades, atribuciones, espacios de poder, ámbitos de decisión, etcétera.

\section{Acceso a la justicia y violencia institucional}

En los tiempos que nos corren resulta imperativo colocar en el eje de debate las cuestiones de género vinculadas con la violencia hacia las mujeres y el deficiente acceso a la justicia que gira en torno a esta problemática.

La creación de normas androcéntricas ${ }^{3}$, la aplicación sexista del derecho y la misma praxis jurídica, han fomentado que sea el propio Estado a través de sus instituciones, quien reproduzca sistemáticamente distintas formas de violencia de género.

No existe un sólo detonante ni una única solución posible. Son varios los factores que se conjugan propiciando este contexto y múltiples las alternativas que pueden elaborarse para abordarlo.

\section{1-El ejercicio desigual del poder}

Históricamente, la redacción y aplicación de normas ha sido llevada a cabo en su amplísima mayoría por varones, una tarea ejecutada según el alcance de sus valores, intereses y cosmovisión, marginándose durante tiempos incalculables los derechos de las mujeres. Es cierto que a partir del siglo XIX con el devenir de las enormes luchas emancipadoras, el escenario ha sufrido algunas variaciones, no obstante, aún se encuentra lejos de cumplir con las expectativas feministas.

\section{2-El Sistema Penal como herramienta imperfecta}

La respuesta punitiva constituye el recurso por excelencia activado por el Estado a la hora de abordar hechos de violencia de género. Se trata de una solución estéril, cuyos límites generan un efecto residual no deseado: si bien es posible que detenga el curso lesivo, no brinda soluciones a mediano y largo plazo. El ejemplo que personifica este fenómeno es la implementación del "botón antipánico", un dispositivo puramente reactivo que introduce a la figura policial cuando el peligro es inminente o el daño ya está tramitándose. De ningún modo esta clase de

3 El androcentrismo consiste en aquella visión del mundo que sitúa al hombre como centro de todas las cosas. Esta concepción de la realidad parte de la idea de que la mirada masculina es la única posible, por lo que se generaliza para toda la humanidad, sea que alcance a hombres o mujeres. Conlleva la invisibilidad de las mujeres y de su mundo y el ocultamiento de los aportes realizados por ellas. Disponible en: http://www.mujeresenred.net/spip.php?article1600 
mecanismo constituye soluciones reales, si no es complementado con una serie de políticas públicas destinadas a frenar esta infame y brutal masacre de la que estamos siendo testigos. Deben llevarse a cabo políticas preventivas, de concientización, que promuevan una nueva perspectiva respetuosa de los derechos de las mujeres, posibilitando la consolidación de un nuevo paradigma cultural.

\section{3-Estereotipos de género y prejuicios sexistas}

Estas categorías se encuentran fuertemente arraigadas en todos los niveles de las instituciones públicas. Tanto estereotipos como prejuicios, resultan determinantes a la hora de evaluar las prácticas de funcionarios y empleados estatales, operadores jurídicos y otros sujetos cuya tarea consiste en la orientación, atención y asistencia de las víctimas, en representación de los organismos públicos. La escasa o nula especialización de los actores intervinientes en materia de género, hace que sea sumamente dificultoso lograr una intervención eficaz, generando efectos no deseados en una multiplicidad de supuestos. Los casos típicos consisten en la desacreditación de la víctima y en los pedidos de reiteración del relato como consecuencia de un desempeño deficiente de las funciones judiciales y administrativas, gestándose así un terreno fértil para los procesos de revictimización. Lo propio sucede en la formación de abogadas y abogados egresados de las distintas facultades del país, constituyéndose como grandes especialistas en derecho, pero carentes de perspectiva de género. De esta forma, es que nos topamos con jueces y fiscales que deben solicitar o aplicar penas altísimas, pero que no conciben el contexto, desconocen sus implicancias y se mantienen al margen de la verdadera problemática de fondo.

\section{4-La inaplicabilidad del positivismo}

La cultura jurídica dominante se ha centrado principalmente en los aspectos técnicos de las normas, desconociendo la existencia de otros elementos esenciales que hacen a su vida y que impiden reducir la problemática a un análisis lógicoformal del texto de la ley. El objeto de estudio de la ciencia jurídica no puede ser apartado de la realidad para circunscribirse únicamente al estudio de la norma. Esto implica que deben tomarse en cuenta no sólo aquellos factores que han dado motivo a su génesis, sino también los que posibilitan su aplicación práctica cotidiana, contemplando incluso aquellos que puedan dar lugar a su ulterior modificación.

\section{5-El rol pasivo de la justicia}

La justicia, coherente con el dogmatismo jurídico, ha asumido un rol más bien formalista, con ausencia o insignificante presencia de componentes de justicia social, circunstancia que atenta de forma directa contra los derechos las minorías. 
A los efectos de atenuar estas vicisitudes, resulta fundamental utilizar el pensamiento crítico para elaborar y aplicar alternativas a las prácticas hegemónicas del derecho y la justicia. Democratizarla parece ser un interesante punto de partida.

\section{6-La importancia de los organismos intermedios: asociaciones y otras entidades no estatales}

Es imposible la obtención de resultados que modifiquen el contexto sin contemplar la incidencia de los factores socioeconómicos que hacen a la marginalidad y la pobreza de los sectores sociales más desfavorecidos. A estos fines, la participación de Asociaciones, ONG, Consultorios Jurídicos Gratuitos y otras entidades que trabajan sobre la problemática, resulta imprescindible a los fines de materializar la concientización de los propios derechos, haciendo posible su posterior ejercicio.

Aunque la violencia de género no constituye un flagelo de clase, bien sabemos que las mujeres que carecen de recursos materiales, se encuentran en una especial situación de vulnerabilidad. Muchas de ellas dedican su vida entera al trabajo en el hogar y la crianza de los hijos, o tienen empleos de medio tiempo o informales sin posibilidad de desarrollo de autosuficiencia, lo que genera en muchos casos, la dependencia económica respecto del agresor. Esta circunstancia hace más dificultosa la salida del círculo de la violencia y es allí donde adquiere vital importancia la inclusión social y laboral.

Desde todos los frentes feministas y las organizaciones que promueven el respeto por los DDHH de las mujeres, se viene reclamando la declaración de la Emergencia en Violencia de Género, una lucha que pese a las estadísticas ${ }^{4}$ y a las masivas y reiteradas manifestaciones del colectivo Ni Una Menos, sigue sin obtener resultados concretos ${ }^{5}$. En el año 2009 se logró la sanción de la Ley 26.485 de Protección Integral contra la Violencia de Género, obligándose así a colocar el tema en la agenda pública. No caben dudas, tanto los femicidios como la violencia hacia las mujeres constituyen fuentes de inseguridad, es por ello necesario que el Estado incremente los recursos destinados a dar respuesta a este conflicto. Sin desconocer su papel central, el panorama tal cual se encuentra planteado hace necesaria la búsqueda del empoderamiento de este colectivo social, de allí la idea de autonomía.

\footnotetext{
4 Según los datos recabados por el Instituto de Políticas de Género Wanda Taddei, solamente en los primeros 43 días de 2017 se cometieron 57 femicidios en el país, arrojando un promedio de una muerte cada 18 horas. Los efectuados en 2016 fueron 322, el 87\% de ellos fueron cometidos por hombres del círculo íntimo de la víctima y conocidos de ellas, el $40 \%$ por la pareja, $26 \%$ ex pareja, $13 \%$ algún conocido. El 17\% de las víctimas había realizado denuncias previas por violencia de género y el $9 \%$ tenía medidas de protección otorgadas por la justicia. Disponible en: http://cosecharoja.org/al-menos-cuatromujeres-fueron-asesinadas-en-las-ultimas-72-horas/
}

5 Aún no se ha sancionado una Ley Nacional que declare la Emergencia en Violencia de Género que funcione como marco referencial para las provincias y establezca un piso mínimo de protección de los derechos. 


\section{Una batalla cultural}

Está claro que para modificar la realidad que nos victimiza día a día a las mujeres, se requiere de la implementación de políticas públicas y del impulso de un cambio cultural que debe abordarse desde lo educativo en los distintos estadios de socialización, más aún en los años fundantes que inciden en la subjetividad de niños, niñas y adolescentes. El colectivo Ni Una Menos a través de la militancia y de las masivas convocatorias que se llevan a cabo desde hace dos años, son signos de una maduración como sociedad, sin embargo, si el Estado no asume el rol que le compete acompañando la lucha mediante la implementación de dichas políticas, es prácticamente imposible reducir los índices. En la provincia de Buenos Aires tenemos la ley 14.772 del año 2015, que creó el programa “\#NiUnaMenos" estructurado sobre los conceptos de "perspectiva de género", "derechos de las mujeres" y "erradicación de la violencia" y se estableció la obligatoriedad de abordar estos temas desde el nivel de educación inicial, hasta la universitaria inclusive. A pesar de su recepción normativa, estas actividades de formación y capacitación de niños, niñas, adolescentes y adultos, son de escasa aplicación. Es dable por esto afirmar que si bien es necesaria la creación de marcos legales para la consagración de derechos y la consolidación de la seguridad jurídica, es preciso a su vez crear dispositivos que permitan articularlos en prácticas concretas, evitando que las leyes redunden en letra muerta.

Uno de los modos de consolidar la autonomía feminista es a través de la construcción de espacios que propicien la puesta en común de las propias

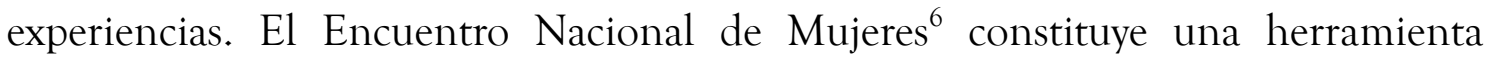
fundamental y necesaria para la creación de una conciencia jurídica feminista. La consigna "Ni Una Menos" también funciona como instancia de lucha y toma de conciencia a los fines de llevar a cabo la manifestación social y solicitar por parte del Estado, la declaración de la Emergencia en Violencia de Género.

En definitiva, se trata de la creación de procesos y herramientas interactivas, de articulación y puesta en común de las experiencias personales, tomando como base las vivencias concretas y los distintos grados de vulnerabilidad, para la creación de significados colectivos, priorizando lo expresado en la práctica, por sobre la abstracción de las metodologías jurídicas tradicionales. Para lograr el empoderamiento de las mujeres es necesario avanzar sobre la construcción de una nueva concepción no androcéntrica del derecho, al mismo tiempo que lo hacemos en la construcción de una esencial e imprescindible justicia de género.

6 El Encuentro Nacional de Mujeres es una modalidad de encuentro única en el mundo, que permite que miles de mujeres autoconvocadas participen de instancias de lucha democráticas, federales, plurales y autofinanciadas. Se realiza cada año durante el mes de octubre en distintas localidades del país. 


\section{Bibliografía}

CONVENCIÓN INTERAMERICANA PARA PREVENIR, SANCIONAR Y ERRADICAR LA VIOLENCIA CONTRA LA MUJER (1996). En el orden nacional, rige la Ley 26.485. Buenos Aires.

Cosecha Roja (2017). Al menos cuatro asesinadas en las últimas 72 horas. En línea en: $\quad$ http://cosecharoja.org/al-menos-cuatro-mujeres-fueron-asesinadas-en-lasultimas-72-horas/

MUJERES EN RED (2008). ¿Qué significa androcentrismo?. En línea en: http://www.mujeresenred.net/spip.php?article1600

OAKEY A. (1972). Sex, Gender and Society. New Society. En línea en: https://www.amazon.es/Sex-Gender-Society-Ann-Oakley/dp/1472435621 